IMPACT OF SAHARAN DUST ON THE INCIDENCE OF ACUTE CORONARY SYNDROME.

IMPACTO DEL POLVO SAHARIANO EN LA INCIDENCIA DEL SÍNDROME CORONARIO AGUDO.

Short title: SAHARAN DUST AND ACUTE CORONARY SYNDROME

Alberto Dominguez-Rodriguez MD,PhD ${ }^{\mathbf{1 , 2 , 3 , + , *}}$, Sergio Rodríguez $\mathrm{PhD}^{\mathbf{4 , 5}}$, Nestor BaezFerrer $\mathrm{MD}^{1}$, Pablo Avanzas MD, $\mathrm{PhD}^{\mathbf{6 , 7 , 8}}$, Pedro Abreu-Gonzalez $\mathrm{PhD}^{9}$, Jacobo Silva MD,PhD ${ }^{\mathbf{6 , 8}}$, Cesar Moris MD,PhD ${ }^{\mathbf{6 , 7},}$, Daniel Hernandez-Vaquero MD,PhD ${ }^{\mathbf{6 , 7 +}}$.

(1) Hospital Universitario de Canarias, Servicio de Cardiología, Tenerife, España.

(2) Facultad de Ciencias de la Salud, Universidad Europea de Canarias, Tenerife, España.

(3) CIBER de enfermedades CardioVasculares (CIBERCV), Madrid, España.

(4) Estación Experimental de Zonas Áridas, EEZA, CSIC, Almería, España.

(5) Instituto de Productos Naturales y Agrobiología, IPNA, CSIC, Tenerife, España.

(6) Área del Corazón. Hospital Universitario Central de Asturias, Oviedo, España.

(7) Instituto de Investigación Sanitaria del Principado de Asturias.

(8) Departamento de Medicina, Universidad de Oviedo, Asturias, España

(9) Departamento de Fisiología , Facultad de Medicina, Universidad de La Laguna, Tenerife, España.

*Corresponding author: Alberto Dominguez-Rodriguez, Hospital Universitario de Canarias, Servicio de Cardiología. Ofra s/n La Cuesta E38320. Tenerife. España. 
Telephone: + 34922679040

Fax: + 34922678460 .

e-mail: adrvdg@hotmail.com

+ Drs. Dominguez-Rodriguez and Hernandez-Vaquero share first authorship.

\section{ACKNOWLEDGEMENT}

We thank to (i) the WMO-SDS WAS program, co-managed by AEMET and BSC, for providing dust modelling and (ii) the Department of Environment of the Government of the Canary Islands for providing air quality data.

\section{CONFLICT OF INTEREST}

None declared. 


\section{ABSTRACT}

Introduction and objectives: Asian desert dust has been recently recognized as a trigger for acute myocardial infarction (AMI). The inflow of dust from the Sahara into Spain causes air quality impairments due to an increase in particulate matter (PM) concentrations in the ambient air. The aim of the present study was to elucidate whether Saharan dust events are associated with the incidence of acute coronary syndrome (ACS) in patients living near North Africa, the major global dust source.

Methods: We prospectively collected data on hospitalizations due to ACS in 2416 consecutive patients from a tertiary care hospital (Canary Islands-Spain) from December 2012 to December 2017. Concentrations of PM smaller than 10 microns aerodynamic diameter $\left(\mathrm{PM}_{10}\right)$ and reactive gases were measured in the European Air Quality Network implemented in the Canary Islands. We applied the time-stratified case crossover design using conditional Poisson regression models to estimate the impact of $\mathrm{PM}_{10}$ Saharan dust events on the incidence of ACS.

Results: The occurrence of Saharan dust events observed 0-5 days before the ACS onset was not significantly associated with the incidence of ACS. Incidence rate ratios (IRR) of $\mathrm{PM}_{10}$ levels one, two, three, four and five days before the ACS onset (for changes in $\left.10 \mu \mathrm{g} / \mathrm{m}^{3}\right)$ were $1.27(0.87-1.85), 0.92(0.84-1.01), 0.74(0.45-1.22), 0.98$ (0.87-1.11) and 0.95 (0.84-1.06), respectively.

Conclusions: Exposure to Saharan desert dust is not associated with the incidence of ACS.

Keywords: African dust. Saharan dust. Acute coronary syndrome. Acute myocardial infarction. 


\section{RESUMEN}

Introducción y objetivos: En Asia el polvo desértico ha sido recientemente reconocido como desencadenante del infarto agudo de miocardio(IAM). En España las entradas de polvo Sahariano están asociadas a empeoramientos en la calidad del aire debido a aumentos en las concentraciones de material particulado(PM) en el aire ambiente. Nuestro objetivo fue dilucidar si los eventos de polvo sahariano están asociados con la incidencia del síndrome coronario agudo(SCA) en pacientes que habitan cerca del Norte de África, la mayor fuente global de polvo desértico.

Métodos: Analizamos prospectivamente los datos de 2416 pacientes consecutivamente hospitalizados por SCA en un hospital terciario (Islas Canarias-España), desde diciembre de 2012 hasta diciembre de 2017. Las concentraciones de PM menores de 10 micras de diámetro aerodinámico $\left(\mathrm{PM}_{10}\right)$ y gases reactivos fueron medidas desde la Red Europea de Calidad del Aire. Aplicamos un diseño mediante estratificación en el tiempo de casos cruzados, utilizando modelos de regresión condicional de Poisson, para estimar el impacto de los eventos de polvo sahariano de $\mathrm{PM}_{10}$ en la incidencia del SCA.

Resultados: La presencia de eventos de polvo sahariano observados desde el mismo día del inicio del SCA hasta 5 días antes del mismo, no mostraron asociación significativa con la incidencia del SCA. El índice de riesgo relativo(IRR) de los niveles de $\mathrm{PM}_{10}$ uno, dos, tres, cuatro y cinco días previo al inicio del SCA (para cambios en $10 \mu \mathrm{g} / \mathrm{m}^{3}$ ) fue $1.27(0.87-1.85), 0.92(0.84-1.01), 0.74(0.45-1.22), 0.98(0.87-1.11)$ у $0.95(0.84-1.06)$, respectivamente.

Conclusiones: La exposición a polvo Sahariano no está asociada con la incidencia del SCA.

Palabras clave: Polvo africano. Polvo sahariano. Síndrome coronario agudo. Infarto agudo del miocardio. 


\title{
Table of abbreviations
}

ACS: acute coronary syndrome

AMI: acute myocardial infarction

IRR: incidence rate ratios

PM: particulate matter

\author{
Abreviaturas \\ SCA: síndrome coronario agudo \\ IAM: infarto agudo de miocardio \\ IRR: índice de riesgo relativo \\ PM: material particulado
}




\section{INTRODUCTION}

The inhalation of air pollutants related to combustion has become a global threat for human health. According to the World Health Organization, particulate matter (PM) smaller than 10 and 2.5 microns aerodynamic diameter $\left(\mathrm{PM}_{10}\right.$ and $\mathrm{PM}_{2.5}$, respectively) has more negative impact on health than gaseous pollutants ${ }^{1}$. In Europe, where PM constitution is mostly dominated by combustion related components (black carbon, organic carbon, sulphate, nitrate, etc. $)^{2}, 15-28 \%$ of total cardiovascular mortality is attributed to air pollution ${ }^{3}$.

Health effects related to the inhalation of desert dust particles blowing in the ambient air -due to dust storms- is an emerging topic of global interest ${ }^{4,5}$. This kind of mineral dust is, by far, the most important contributor to $\mathrm{PM}_{10}$ and $\mathrm{PM}_{2.5}$ concentrations in large subtropical regions, including North Africa, the Middle East and parts of Asia ${ }^{4}$ (see Supplementary material online, Figure S1). Review reports have highlighted the existence of an imbalance between the areas most exposed to desert dust (North Africa) and the areas most studied in terms of health effects, mainly Europe and Asia ${ }^{5}$. For example, Kojima et al. studied the exposure to Asian dust and pointed out that these dust events are likely to be a potential trigger for the onset of acute myocardial infarction (AMI) in patients of the Kumamoto Prefecture (Japan) ${ }^{6}$. Globally, there is a lack of studies near the dust sources ${ }^{5}$.

Global dust emission ranges from 1500 to $2000 \mathrm{Tg} \cdot \mathrm{yr}^{-17}$. North Africa is the largest contributor to the global dust budget, accounting for 50 to $70 \%$ global emissions. North African dust is regularly transported over the North Atlantic (resulting in typical concentrations $10 \mathrm{~s}$ to $100 \mathrm{~s} \mu \mathrm{g} / \mathrm{m}^{3}$ ), and episodically over the Mediterranean and Europe (typical concentrations $\left.\sim 10 \mathrm{~s} \mu \mathrm{g} / \mathrm{m}^{3}\right)^{8}$. 
The Canary Islands are located in the North Atlantic (Figure 1), under the influence of Atlantic trade winds, a feature that contributes to the occurrence of low background levels of $\mathrm{PM}_{10}$ and $\mathrm{PM}_{2.5}\left(\sim 15\right.$ and $8 \mu \mathrm{g} / \mathrm{m}^{3}$, respectively), i.e. $\sim$ good air quality conditions. However, the Islands are very close to North Africa ( $500 \mathrm{~km})$, and receive frequent impacts of dusty air from the Sahara Desert, a scenario that leads to increases in $\mathrm{PM}_{10}$ and $\mathrm{PM}_{2.5}$ concentrations, that can reach values over $100 \mathrm{~s} \mu \mathrm{g} / \mathrm{m}^{3}$, i.e. These PM concentrations are much higher than those occurring in Europe and higher than the $50 \mu \mathrm{g} / \mathrm{m}^{3}$ for $\mathrm{PM}_{10}$ recommended as daily limit value in the Air Quality Guideline of the World Health Organization ${ }^{1}$. These features offer an ideal opportunity to investigate the effects of dust on the cardiovascular disease in the populations living near major dust sources ${ }^{9}$. In the present study, we designed a time-stratified case-crossover study to elucidate the association between exposure to Saharan dust and the incidence of acute coronary syndrome (ACS) in patients living near North Africa, the major global dust source.

\section{METHODS}

\section{Study area}

The Canary Islands are a volcanic archipelago placed in the eastern North Atlantic (Figure 1). This study was performed in Tenerife, the largest island (2034.38 $\mathrm{Km}^{2}$ ). Meteorology is characterized by trade winds (March to August), which contribute to the rapid dispersion of local air pollutants and contribute to keep a rather good air quality in most of the archipelago. Although dust events may occur through the year, there are two dust seasons ${ }^{10}$, segregated by meteorology: (i) November to March, and (ii) July to August. 


\section{Patient data}

The study was carried out in a tertiary care hospital (Tenerife - Spain), which provides medical care for the residents in the northern part of the island of Tenerife, serving a population of 343,025 inhabitants. The northern side of Tenerife includes many residential areas, so many of their inhabitants commute every morning to work in other parts of the islands (mostly to the capital, Santa Cruz, and the Southern part of Tenerife), so they are expose to air quality conditions throughout the Island. Our study included all patients diagnosed of ACS, with or without AMI, from December 2012 to December 2017 at that institution. AMI was defined according to current guidelines, as the presence of symptoms of myocardial ischemia and an increase of myocardial necrosis biomarkers ${ }^{11,12}$.

A number of clinical variables were prospectively recorded in each patient, including coronary risk factors, age, gender, previous vascular disease, presence of asthma or chronic obstructive pulmonary disease, chronic kidney disease, atrial fibrillation, number of diseased coronary vessels (recorded from the coronariography), left ventricular ejection fraction, Killip class, levels of troponin I, coronary intervention (percutaneous transluminal coronary angioplasty or coronary artery bypass surgery), hospital stay, inhospital mortality and 1-year mortality.

This study was approved by the Clinical Research Ethics Committee of a tertiary care hospital.

\section{Air quality, desert dust and meteorological variables}

Data on meteorology, concentrations of $\mathrm{PM}_{10}, \mathrm{PM}_{2.5-10}, \mathrm{PM}_{2.5}$ and reactive gasesous pollutants $\left(\mathrm{NO}_{\mathrm{x}}, \mathrm{O}_{3}\right.$, and $\left.\mathrm{SO}_{2}\right)$ were prospectivelly collected daily from December 2012 to December 2017. These data were provided by the air quality network 
of the Canary Islands, which is part of the European Air Quality Network, in which particulate $\left(\mathrm{PM}_{10}\right.$ and $\left.\mathrm{PM}_{2.5}\right)$ and gaseous pollutants are monitored following the mandatory reference methods and procedures stablished by the European Union legislation (Directive 2008/50/EC). The network provides hourly resolution data, which are transmited to the European Environmental Agency. We determined and analysed daily averaged values. In order to have a comprehensive view of the impact of Saharan dust events on air quality, we initillay worked with the data of several air quality stations, located in the North (Balsa Zamora, residental background), North-East (Deposito Tristan and Tena Artigas, residential background) and South (E1 Rio, rural) of Tenerife. Because of the rather low background of PM and because Saharan dust events prompt high PM concentrations across the island, the time series of PM at these sites exibited a high correlation. Thus, we selected the records with the highest data availability (Tena Artigas station) to be included in the statistical analysis with the medical data. During the study period, the time series of daily $\mathrm{PM}_{10}$ concentrations of Tena Artigas (availability $=98.4 \%$ ) exibited a correlation coeficient within the range $0.76-0.84$ with the other three stations during the study period (December 2012 to December 2017). The occurrence of Saharan dust events was detected with the validated past forecasts of the WMO SDS-WAS (World Meteorological Organization's Sand and Dust Storm - Warning Advisory and Assessment System; see Supplementary material online, Figure S1), whose regional node for Northern Africa, Middle East and Europe is managed by the Meteorological State Agency of Spain and the Barcelona Super Computing Centre. The WMO SDS-WAS dust forecast system is constituted by a weather forecast model which also includes a module for simulating the dust (cycle emissions, transport and deposition $)^{13}$. This dust forecast for the Canary Islands was validated by García-Castrillo and Terradellas ${ }^{14}$. 


\section{Statistical analysis}

Quantitative and categorical variables were respectively described as median (interquartile range) and number (percentage). We used time series regression analyses, which are commonly used to study the association between aggregated exposures and health outcomes. The outcome is a count (usually number of events per day) and the main unit of analysis is the day and not the individual person. Because usual individual confounders (age, sex, diabetes, etc) do not change significantly from day to day, these factors do not have any impact on effect estimates of environment variables. To control for seasonality and long-term trends, we used a time-stratified case cross-over design being the strata the day of the week between month ${ }^{15,16}$. The idea was to compare a case's exposure immediately prior to the event with that same person's exposure at otherwise similar "references" times. Being our strata the day of the week within months, exposures associated with an event occurring one day of the week, for example, a Monday, were compared with exposures of the rest of the Mondays of the same month and used as references. These strata were expected to control for individual covariates and slow or regular changes in underlying risk, such as season, trends over time, or day of the week ${ }^{15,16}$.

A conditional logistic regression model is usually used to analyze the impact of environment variables on clinical events. However, due to the influence of unmeasured causes of clinical events that vary over time, observed event counts have usually a greater variation than the predicted by a Poisson distribution ${ }^{15,16}$. This over-dispersion, when using a logistic regression model, is not taken into account because outcomes are binary and then, over-dispersion is not apparent. However, the assumption of independence between case-control sets in a conditional logistic model implicitly assumes no over-dispersion of counts ${ }^{16}$. Moreover, conditional logistic regression 
assumes that observations are independent. However, observations close in time are probably more similar than those distant in $\operatorname{time}^{17}$ and autocorrelation is likely to be present. In such scenario, the usual conditional logistic regression model cannot adjust for over-dispersion and autocorrelation, both frequent causes of underestimating uncertainty or type 1 error $^{16}$.

To overcome all these methodological limitations, following the method published by Armstrong et al. ${ }^{16}$, we used a conditional Poisson regression model to control for over-dispersion and autocorrelation. The dependent variable is the number of ACS diagnosed at the institution per day. In order to perform this analysis, data matrix had to be modified (see Supplementary material online, Figure S2). We calculated incidence rate ratios (IRR) with 95\% confidence intervals (CI). To know the influence of $\mathrm{PM}_{10}$, we adjusted for the following pollutants and environment variables: $\mathrm{PM}_{2,5-10}$, $\mathrm{PM}_{2,5}, \mathrm{NO}_{2}, \mathrm{SO}_{2}, \mathrm{O}_{3}$, temperature and humidity. The maximum model was constructed with $\mathrm{PM}_{10}$, the previously described pollutants and environment variables and the twoway interactions between $\mathrm{PM}_{10}$ and all other variables. All these interactions were assessed and removed if statistical significance was not found. We also took in account the possibility that the impact of the particles was delayed a few days. Thus, we studied the single-day lag effect from day 0 to day 5 . We also adjusted these different lageffects for each other, developing a lag-stratified distributed lag model ${ }^{16}$. However, in this last model, lag-terms are likely to be highly correlated. To reduce collinearity of these lag-terms, which results in imprecise estimates, we imposed some constraints to the distributed lag model, namely that effect estimates for day 1 and 2 are the same, and effect estimates for day 3-5 are also the same ${ }^{16}$. We repeated all analyses calculating the incidence of AMI instead of ACS. Diagnostics of the model were tested. P value $<0.05$ was considered statistically significant. All analyses were performed using STATA 
v.15® (StataCorp, Tx, USA).

\section{RESULTS}

\section{Study population, ACS, PM $M_{10}$ and dust events}

During the study period, 2416 patients were diagnosed of ACS at the aforementioned institution. The median of age was 64 (54-74) years and $649(26.86 \%)$ were women. A total of $1350(55.88 \%)$ had AMI, 185 (7.67\%) were admitted in III or IV Killip class and 129 (5.34\%) patients died during the hospital admission. These and other variables are described in Table 1.

In the study period, there were 485 days $(26.75 \%)$ in which there was no ACS, 621 days (34.25\%) in which there was $1 \mathrm{ACS}, 428$ days $(23.61 \%)$ in which there were 2 ACS, 200 days (11.03\%) in which there were 3 ACS, 60 days $(3.31 \%)$ in which there were 4 ACS, 15 days $(0.83 \%)$ in which there were 5 ACS and 4 days $(0.22 \%)$ in which there were 6 ACS. The median of the $\mathrm{PM}_{10}$ levels was $15 \mu \mathrm{g} / \mathrm{m}^{3}$ (11-24). For those days without ACS, $\mathrm{PM}_{10}$ concentration was $15 \mu \mathrm{g} / \mathrm{m}^{3}$ (11-23). For days with 1, 2, 3, 4, 5 or 6 ACS, $\mathrm{PM}_{10}$ levels were $16 \mu \mathrm{g} / \mathrm{m}^{3}$ (11-24), $16 \mu \mathrm{g} / \mathrm{m}^{3}$ (11-23), $16 \mu \mathrm{g} / \mathrm{m}^{3}$ (11-24), 16 $\mu \mathrm{g} / \mathrm{m}^{3}$ (11-24) and $13 \mu \mathrm{g} / \mathrm{m}^{3}$ (10-23), respectively. Table 2 shows $\mathrm{PM}_{10}$ concentrations for different numbers of ACS/day and different day-lags.

Figure S3A (supplementary material online) shows the daily $\mathrm{PM}_{10}$ concentrations in Tenerife during the study period. This time series of $\mathrm{PM}_{10}$ shows the regular low background of this region $\left(\sim 15 \mu \mathrm{g} / \mathrm{m}^{3}\right)$ and sharp peak events due to the arrival of dusty air from North Africa, when $\mathrm{PM}_{10}$ reached values between 40 and $350 \mu \mathrm{g} / \mathrm{m}^{3}$. Figure $S 3 B$ (supplementary material online) shows the time series of dust concentrations at Tenerife provided by the WMO SDS-WAS modelling, where the peak dust events (up to $\sim 320 \mu \mathrm{g} / \mathrm{m}^{3}$ ) lead to the high $\mathrm{PM}_{10}$ episodes, as can be clearly 
observed.

\section{Influence of Saharan dust on ACS incidence}

In the same day of the ACS (with no lag-effect), the IRR for each $10 \mu \mathrm{g} / \mathrm{m}^{3}$ of $\mathrm{PM}_{10}$ was 1.01 (95\%CI 0.80-1.28). Results of the Poisson regression showing IRR of $\mathrm{PM}_{10}$ and others confounding factors are shown in Table 3. No long-term trends between the study period and the predicted number of ACS were observed (Figure 2).

Studying possible day-lag effects, $\mathrm{PM}_{10}$ concentrations were not associated with the number of ACS in any of the previous 5 days. IRR of $\mathrm{PM}_{10}$ levels of the one, two, three, four and five days (for changes in $\left.10 \mu \mathrm{g} / \mathrm{m}^{3}\right)$ were $1.27(0.87-1.85), 0.92(0.84-$ $1.01), 0.74(0.45-1.22), 0.98(0.87-1.11)$ and $0.95(0.84-1.06)$, respectively. No association between $\mathrm{PM}_{10}$ and number of ACS was found when these different lageffects were adjusted by each other in a model with constraints (effect estimates for daylag 0,1 and 2 are the same, and for day-lag 3, 4 and 5 are the same). Figure 3 shows the IRR, which result of modelling lagged associations between $\mathrm{PM}_{10}$ and number of ACS. Interactions were not statistically significant in any of the models and were eliminated.

A total of 1350 patients were diagnosed of AMI. Based on the Poisson regression model adjusted for autocorrelation and over-dispersion, $\mathrm{PM}_{10}$ levels had no influence on the number of AMI. For $10 \mu \mathrm{g} / \mathrm{m}^{3}$ of $\mathrm{PM}_{10}$, the IRR was 1.1 (CI95\% 0.71 1.55). The number of AMI was not associated with the $\mathrm{PM}_{10}$ concentrations of any of the previous 5 days. No association between $\mathrm{PM}_{10}$ and number of ACS was found when these different lag-effects were adjusted by each other in a model with constraints (Figure 4). 


\section{DISCUSSION}

This study holds that desert dust is not a potential trigger for the onset of ACS in patients exposed to Saharan dust in Tenerife-Spain. Recently, special attention has been given to non- anthropogenic air pollution originating from natural dust storms, which may constitute a health risk threat ${ }^{5,18}$. The majority of the environmental research analyzing the effects of air pollution on cardiovascular health focuses on anthropogenic air pollution (i.e. linked to combustion of fossil fuels, e.g. transport, industry, etc). In the current study we analyzed the possibility that Saharan dust produced by natural phenomena is a trigger of ACS.

Generally speaking, a distinction is made between particles smaller than 10 microns in diameter $\left(\mathrm{PM}_{10}\right.$, thoracic particles that can penetrate into the lower respiratory system), particles smaller than 2.5 microns $\left(\mathrm{PM}_{2.5}\right.$, so-called fine or respirable particles that can penetrate into the gas-exchange region of the lung), and ultrafine particles smaller than $100 \mathrm{~nm}$ (0.1 microns) that typically have a low contribution to particle-PM mass (i.e. $\mathrm{PM}_{10}$ and $\mathrm{PM}_{2.5}$ ) but are the most abundant and have high grade of lung penetration ${ }^{19}$. Most of anthropogenic -combustion relatedparticle occurs in the ultrafine and $\mathrm{PM}_{2.5}$ fractions, whereas a significant fraction of mineral dust occurs in the coarse range (2.5-10 microns) of $\mathrm{PM}_{10}$. For example, during Saharan dust events, most of the $\mathrm{PM}_{10}$ is constituted by coarse dust particles( $70-80 \%$, i.e. $\left.\mathrm{PM}_{2.5} / \mathrm{PM}_{10}=0.2-0.3\right)$. In contrast, in cities polluted by combustion sources of Europe, $\mathrm{PM}_{10}$ is mostly produced by combustion particles $\left(\mathrm{PM}_{2.5} / \mathrm{PM}_{10}=0.8-0.9\right)^{2}$. Coarse particles are more likely to be deposited in the bronchial passages and thereby induce respiratory conditions such as asthma, chronic obstructive pulmonary disease, and pneumonia ${ }^{19}$.

Papers published to date providing information on health-related PM research 
have focused on the impact of anthropogenically generated -mostly combustion$\mathrm{PM}^{3,20-22}$. Conclusions of these studies were highly concordant and showed that PM derived from combustion is clearly a threat for human health. For example, a recent study by Bañeras et al. ${ }^{23}$ performed in an urban area of the North of Spain, without a natural source of dust, found that $\mathrm{PM}_{10}$ and $\mathrm{PM}_{2,5}$ were associated with the incidence of AMI. PM of urban areas is derived from combustion emissions ${ }^{2}$. The influence of $\mathrm{PM}_{10}$ derived from combustion on cardiovascular pathophysiology is likely to be different from the influence of $\mathrm{PM}_{10}$ derived from natural sources ${ }^{5}$.

Studies based on the influence of PM derived from non-anthropogenic sources are scarce and discordant. A study in USA has shown an association between $\mathrm{PM}_{10}$ derived from dust storms and mortality ${ }^{24}$ while other study analyzing 13 southern European countries has found no association between $\mathrm{PM}_{10}$ concentrations derived from the desert and hospital admissions or mortality ${ }^{25}$.

Recently, two reports have examined the relationship of dust storm with $\mathrm{ACS}^{6,25}$. Vodonos et $\mathrm{al}^{26}$ showed that there was an impact of $\mathrm{PM}_{10}$ (1 day-lag) during dust storm days on the incidence of $\mathrm{ACS} ; \mathrm{OR}=1.007$ (95\%CI 1.002-1.012), while there was no significant effect during non-dust storm days $(\mathrm{OR}=1.011,95 \% \mathrm{CI} 0.998-1.025)$. The authors hypothesized that traffic and industry related particles have more toxic effects on human health ${ }^{26}$ than non-anthropogenic sources. A similar hypothesis was exposed by Kojima et al. These authors, which studied the effect of the Asian dust on the incidence of AMI in the Kumamoto Prefecture (south-western Japan) ${ }^{6}$, concluded that the occurrence of Asian dust events the day before leads to AMI $(\mathrm{OR}=1.46 ; 95 \% \mathrm{CI}$ 1.09-1.95). They controlled for $\mathrm{PM}_{2,5}$ but they did not control for other possible confounding factors such as $\mathrm{PM}_{10}$ or $\mathrm{PM}_{2.5-10}$. There is an "environmental" agreement to consider a dust event based on the mean $\mathrm{PM}_{10}$ concentrations over $24 \mathrm{~h}^{5}$. Moreover, it is 
hard to believe that Asian dust can be a risk factor the day before the AMI (1 day-lag effect) but almost a protector factor the same day of the AMI (0 day-lag effect), as can be drawn from the confidence intervals of their Supplementary Figure $2^{6}$. Statistically significant but incongruent results may occur due to the performance of multiple comparisons, especially in the presence of an underestimated uncertainty, which occurs when over-dispersion and autocorrelation is not taken into account.

Due to the ambiguous language in relation to the so-called dust event, the confusion about the type of particles constituting a dust event and the existence of possible unmeasured or uncontrolled confounding factors, epidemiological associations between desert dust and ACS are quite controversial and inconclusive. In this context, we thought that studying the impact of Saharan dust events in West Africa, where dust events are more frequent and intense than anywhere else in the world ${ }^{4,5}$, could shed light on this issue. We considered dust event as $\mathrm{PM}_{10}$ concentrations ${ }^{5}$, controlled for the existence of possible confounding factors (mainly other PM and pollutants) and used a novel and adequate statistical process that allows not to underestimate the type 1 error $^{15-}$ 17. In addition, this study is based in a single tertiary hospital, which serves all population in the region, thus eliminating selection bias. Likewise, the exposure analyzed in our study comes from non-anthropogenic nature with most of the dust storm originated from the Saharan Desert.

This study has some limitations. First, we used outdoor air pollution concentrations measured at fixed point monitors, whereas people spend most of the time indoors. Second, exposure measurement error is an inherent disadvantage of time-series studies, because the average of selected fixed monitoring stations does not reflect the true average exposure of the population. So, there is some evidence that exposure measurement error in time-series analysis could bias estimates downward ${ }^{27}$. Using 
Poisson regression analysis allows us to control for over-dispersion and autocorrelation, frequent causes of underestimating type 1 error. However, to do it, data matrix had to be modified and a stratified analysis by individual variables could not be performed since these variables no longer make sense in that new data matrix. Finally, we cannot rule out insufficient statistical power to show associations. This lack of statistical power is not trivial and causes a challenge in this kind of studies ${ }^{28}$. With a study period of 5 years and more than 2000 events, we have studied the influence of changes of $10 \mu \mathrm{g} / \mathrm{m}^{3} \mathrm{PM}_{10}$ on the incidence of ACS being the median of $\mathrm{PM}_{10}$ in our territory of $15 \mu \mathrm{g} / \mathrm{m}^{3}$ (11-24). That is, a supposed increase of 10 units of $\mathrm{PM}_{10}$, would be equivalent to moving from a day with relatively little $\mathrm{PM}_{10}$ (imagine 11 units, within the first quartile of $\mathrm{PM}_{10}$ ) to a day with relatively much $\mathrm{PM}_{10}$ (imagine 21 , within almost the third quartile from $\mathrm{PM}_{10}$ ). And even so, the confidence intervals are not excessively wide and none of the associations evaluated have been statistically significant. Nevertheless, the associations between PM and cardiovascular events are generally very small, usually in the third decimal place of the RR, and therefore we cannot rule out a lack of statistical power.

\section{CONCLUSION}

This negative study, the first to assess the impact of Saharan dust events as a potential trigger for the onset of ACS, shows that African dust is unlikely to be associated with the incidence of ACS. Efforts should focus on reducing emissions derived from combustion. 


\section{Key Points}

\section{What is known about the topic?}

- Sahara dust transport may greatly increase the ambient levels of particulate matter recorded in air quality monitoring networks. This is especially relevant in Southern Europe and in some Atlantic islands.

- Most of studies have been performed in regions (Southern Europe and East Asia) distant to dust sources

- Globally, the highest dust concentrations occur in North Africa and none dust health effects study has been performed in the region.

- Studies on dust and health effects have mostly been epidemiological, associating cardiovascular mortality to dust.

\section{What does this study add?}

- In this prospective, observational, study, the occurrence of Saharan dust events observed 0-5 days before the acute coronary syndrome onset was not significantly associated with the incidence of acute coronary syndrome.

- In the air quality studies, the use of appropriate statistical techniques is highly important to control for seasonality and autocorrelation of observations.

- The replication and publication of rigorous studies, even those with "negative" results, enables clarification of the relationships and avoids potential biases. 


\section{REFERENCES}

1. WHO: World Health Organization.http://www.euro.who.int/en/healthtopics/environment-and-health/air-quality/publications/2017/evolution-of-who-airquality-guidelines-past,-present-and-future-2017.

2. Putaud JP, Van Dingenen R, Alastuey A, et al. A European aerosol phenomenology - 3: physical and chemical characteristics of particulate matter from 60 rural, urban, and kerbside sites across Europe. Atmos Environ 2010;44:1308-1320.

3. Lelieveld J, Klingmüller K, Pozzer A, et al. Cardiovascular disease burden from ambient air pollution in Europe reassessed using novel hazard ratio functions. Eur Heart J 2019;40:1590-1596.

4. De Longueville F, Hountondji YC, Henry S, Ozer P. What do we know about effects of desert dust on air quality and human health in West Africa compared to other regions? Sci Total Environ 2010;409:1-8.

5. De Longueville F, Ozer P, Doumbia S, Henry S. Desert dust impacts on human health: an alarming worldwide reality and a need for studies in West Africa. Int $J$ Biometeorol 2013;57:1-19.

6. Kojima S, Michikawa $\mathrm{T}$, Ueda $\mathrm{K}$, et al. Asian dust exposure triggers acute myocardial infarction. Eur Heart J 2017;38:3202-3208.

7. Huneeus N, Schulz M, Balkanski Y, et al. Global dust model intercomparison in AeroCom phase I. Atmos Chem Phys 2001;11: 7781-7816.

8. Engelstaedter S, Tegen I, Washington R. North African dust emissions and transport. Earth Sci Rev 2006;79:73-100.

9. Baldasano JM, Massagué J. Trends and patterns of air quality in Santa Cruz de Tenerife (Canary Islands) in the period 2011-2015. Air Qual Atmos Health 2017;10:939-954. 
10. Rodríguez S, Cuevas E, Prospero JM, et al. Modulation of Saharan dust export by the North African dipole. Atmos Chem Phys 2015;15:7471:7486.

11. Thygesen K, Alpert JS, Jaffe AS, et al. Third universal definition of myocardial infarction. Eur Heart J 2012;33:2551-2567.

12. Roffi M, Patrono C, Collet JP, et al. 2015 ESC Guidelines for the management of acute coronary syndromes in patients presenting without persistent ST-segment elevation: Task Force for the Management of Acute Coronary Syndromes in Patients Presenting without Persistent ST-Segment Elevation of the European Society of Cardiology (ESC). Eur Heart J 2016;37:267-315.

13. Pérez C, Haustein K, Janjic Z, et al. Atmospheric dust modeling from meso to global scales with the online NMMB/BSC-Dust model - Part 1: Model description, annual simulations and evaluation. Atmos Chem Phys 2011;11:13001-13027.

14. García-Castrillo G, Terradellas E. Evaluation of the dust forecasts in the Canary Islands. Technical Report. No: SDS-WAS-2017-0002. 27-June-2017. https://sdswas.aemet.es/materials/technical-reports/SDSWASNAMEE20170002.pdf.

15. Lu Y, Zeger SL. On the equivalence of case crossover and time series methods in environmental epidemiology. Biostatistics 2007;8:337-344.

16. Armstrong BG, Gasparrini A, Tobias A. Conditional Poisson models: a flexible alternative to conditional logistic case cross-over analysis. BMC Med Res Methodol 2014; $14: 122$.

17. Bhaskaran K, Gasparrini A, Hajat S, Smeeth L, Armstrong B. Time series regression studies in environmental epidemiology. Int J Epidemiol 2013;42:11871195.

18. Perez L, Tobias A, Querol X, et al. Coarse particles from Saharan dust and daily mortality. Epidemiology 2008;19:800-807. 
19. Pope CA 3rd, Dockery DW. Health effects of fine particulate air pollution: lines that connect. J Air Waste Manag Assoc 2006;56:709-742.

20. Münzel T, Gori T, Al-Kindi S, et al. Effects of gaseous and solid constituents of air pollution on endothelial function. Eur Heart $J$ 2018;39:3543-3550.

21. Dominguez-Rodriguez A, Abreu-Gonzalez P, Rodríguez S, Avanzas P, Juarez-Prera RA. Short-term effects of air pollution, markers of endothelial activation, and coagulation to predict major adverse cardiovascular events in patients with acute coronary syndrome: insights from AIRACOS study. Biomarkers 2017;22:389-393.

22. Domínguez-Rodríguez A, Abreu-Afonso J, Rodríguez S, et al. Comparative study of ambient air particles in patients hospitalized for heart failure and acute coronary syndrome. Rev Esp Cardiol 2011;64:661-666.

23. Bañeras J, Ferreira-Gonzalez I, Marsal JR et al. Short-term exposure to air pollutants increases the risk of ST elevation myocardial infarction and of infarctrelated ventricular arrythmias and mortality. Int J Cardiol. 2018;250:35-42.

24. Crooks JL, Cascio WE, Percy MS, Reyes J, Neas LM, Hilborn ED. The association between dust storms and daily non-accidental mortality in the United States, 19932005. Environ Health Perspect 2016;124:1735-1743.

25. Stafoggia M, Zauli-Sajani S, Pey J, et al. Desert dust outbreaks in southern Europe: contribution to daily $\mathrm{PM}_{10}$ concentrations and short-term associations with mortality and hospital admissions. Environ Health Perspect 2016;124:413-419.

26. Vodonos A, Friger M, Katra I, et al. Individual effect modifiers of dust exposure effect on cardiovascular morbidity. PLoS One 2015;10:e0137714.

27. Zeger SL, Thomas D, Dominici F, et al. Exposure measurement error in time-series studies of air pollution: concepts and consequences. Environ Health Perspect 2000;108:419-426. 


\section{Rev Esp Cardiol 2020, in press \\ https://doi.org/10.1016/j.rec.2020.02.003}

28. Winquist A, Klein M, Tolbert P, Sarnat SE. Power estimation using simulations for air-pollution time-series studies. Environ Health. 2012;11:68. 


\section{TABLES}

Table 1: Population characteristics.

\begin{tabular}{|c|c|}
\hline \multicolumn{2}{|l|}{ Variable } \\
\hline \multicolumn{2}{|l|}{ Previous known factors } \\
\hline Age (years) & $64(54-74)$ \\
\hline Women & $649(26.86 \%)$ \\
\hline Hypertension & $1542(63.85 \%)$ \\
\hline Dyslipidemia & $1400(57.97 \%)$ \\
\hline Diabetes & $883(36.56 \%)$ \\
\hline Asthma & $82(3.4 \%)$ \\
\hline Chronic obstructive pulmonary disease & $132(5.47 \%)$ \\
\hline Chronic kidney disease & $255(10.57 \%)$ \\
\hline Known previous coronary artery disease & $674(27.92 \%)$ \\
\hline Atrial fibrillation & $149(6.17 \%)$ \\
\hline \multicolumn{2}{|l|}{ Factors related to hospital admission } \\
\hline Acute myocardial infarction & $1350(55.99 \%)$ \\
\hline \multicolumn{2}{|l|}{ Left ventricular ejection fraction } \\
\hline$\geq 50 \%$ & $1758(75.74 \%)$ \\
\hline $35 \%-50 \%$ & $458(19.73 \%)$ \\
\hline$<35 \%$ & $105(4.52 \%)$ \\
\hline \multicolumn{2}{|l|}{ Killip class } \\
\hline I & $2069(85.71 \%)$ \\
\hline II & $158(6.55 \%)$ \\
\hline III & $48(1.99 \%)$ \\
\hline IV & $137(5.68 \%)$ \\
\hline \multicolumn{2}{|l|}{ Coronary artery disease at admission } \\
\hline No coronary disease & $178(7.79 \%)$ \\
\hline
\end{tabular}


One vessel disease

Two vessel disease

Three vessel disease

Peak troponin I (ng/ml)

Treated with percutaneous transluminal coronary

angioplasty.

Treated with coronary artery surgery

Hospital stay (days)

Intrahospital mortality

1-year mortality among survivors
$1048(45.84 \%)$

$600(26.25 \%)$

$460(20.12 \%)$

$8.3(0.5-37.7)$

$1642(68.02 \%)$

$170(7.04 \%)$

$7(5-12)$

$129(5.34 \%)$

$18(0.75 \%)$ 
Table 2. $\mathrm{PM}_{10}$ concentrations based on the number of ACS per day. Data are presented for different day-lags.

\begin{tabular}{|c|c|c|c|c|c|c|}
\hline & $\begin{array}{c}\text { No ACS/day } \\
(n=485 \\
26.75 \%)\end{array}$ & $\begin{array}{l}1 \text { ACS/day } \\
(n=621, \\
34.25 \%)\end{array}$ & $\begin{array}{c}2 \text { ACS } / \text { day } \\
(n=428, \\
23.61 \%)\end{array}$ & $\begin{array}{c}3 \text { ACS/day } \\
(n=200, \\
11.03 \%)\end{array}$ & $\begin{array}{c}4 \text { ACS/day } \\
(n=60, \\
3.31 \%)\end{array}$ & $\begin{array}{c}\text { 5-6 ACS/day } \\
(n=19, \\
1.05 \%)\end{array}$ \\
\hline \multicolumn{7}{|c|}{ Day of admission } \\
\hline $\mathrm{PM}_{10}\left(\mu \mathrm{g} / \mathrm{m}^{3}\right)$ & $15(11-23)$ & $16(11-24)$ & $16(11-23)$ & $16(11-24)$ & $16(11-24)$ & $13(10-23)$ \\
\hline \multicolumn{7}{|l|}{ 1-day lag } \\
\hline $\mathrm{PM}_{10}\left(\mu \mathrm{g} / \mathrm{m}^{3}\right)$ & $15(11-24)$ & $16(11-23)$ & $15(10-23)$ & $16(11-23)$ & $17(11-25)$ & $14(11-17)$ \\
\hline \multicolumn{7}{|l|}{ 2-day lag } \\
\hline $\mathrm{PM}_{10}\left(\mu \mathrm{g} / \mathrm{m}^{3}\right)$ & $16(11-25)$ & $15(11-24)$ & $16(11-23)$ & $15(12-22)$ & $15(9-24)$ & $14(13-18)$ \\
\hline \multicolumn{7}{|l|}{ 3-day lag } \\
\hline $\mathrm{PM}_{10}\left(\mu \mathrm{g} / \mathrm{m}^{3}\right)$ & $15(10-26)$ & $15(10-23)$ & $16(11-23)$ & $16(12-22)$ & $16(12-25)$ & $15(12-18)$ \\
\hline \multicolumn{7}{|l|}{ 4-day lag } \\
\hline $\mathrm{PM}_{10}\left(\mu \mathrm{g} / \mathrm{m}^{3}\right)$ & $15(10-25)$ & $15(10-23)$ & $15(11-24)$ & $15(11-23)$ & $16(11-24)$ & $16(13-19)$ \\
\hline \multicolumn{7}{|l|}{ 5-day lag } \\
\hline $\mathrm{PM}_{10}\left(\mu \mathrm{g} / \mathrm{m}^{3}\right)$ & $15(10-24)$ & $16(11-23)$ & $15(11-23)$ & $15(11-26)$ & $15(11-20)$ & $15(12-28)$ \\
\hline
\end{tabular}

ACS: Acute coronary syndromes; $\mathrm{n}$ : Number of days; $\mathrm{PM}_{10}$ : PM with an aerodynamic diameter $<10 \mu \mathrm{g} / \mathrm{m}^{3}$. 
Table 3. Poisson regression analysis. No day-lag effect.

\begin{tabular}{lcc}
\hline Variable & IRR & $\mathbf{9 5 \%}$ CI \\
\hline $\mathrm{PM}_{10}\left(\mu \mathrm{g} / \mathrm{m}^{3}\right)$ & 1.01 & $0.80-1.28$ \\
$\mathrm{PM}_{2.5}\left(\mu \mathrm{g} / \mathrm{m}^{3}\right)$ & 0.97 & $0.81-1.17$ \\
$\mathrm{PM}_{2.5-10}\left(\mu \mathrm{g} / \mathrm{m}^{3}\right)$ & 1.01 & $0.76-1.36$ \\
$\mathrm{SO}_{2}\left(\mu \mathrm{g} / \mathrm{m}^{3}\right)$ & 0.96 & $0.91-1.02$ \\
$\mathrm{NO}_{2}\left(\mu \mathrm{g} / \mathrm{m}^{3}\right)$ & 1 & $0.98-1.02$ \\
$\mathrm{O}_{3}\left(\mu \mathrm{g} / \mathrm{m}^{3}\right)$ & 1 & $0.99-1.01$ \\
${\mathrm{Temperature}\left({ }^{\circ} \mathrm{C}\right)}_{\mathrm{Humidity}(\%)}$ & 0.97 & $0.92-1.02$ \\
\hline
\end{tabular}

IRR of PM variables was calculated for changes of $10 \mu \mathrm{g} / \mathrm{m}^{3}$ 


\section{FIGURE LEGENDS}

Figure 1: Global distribution of areas with air quality impairment due to desert dust. Arrow highlights main transport pathways. Black circle points the location of Tenerife.

Figure 2: Predicted number of ACS/day during the study period based on the Poisson regression model. Line shows a lowest function.

Figure 3: IRR calculated modelling lagged associations between $\mathrm{PM}_{10}$ concentrations and number of ACS. A: without controlling for other lag-effects, B: controlling for different lag-effects with constraints. IRR for changes in $10 \mu \mathrm{g} / \mathrm{m}^{3}$ of $\mathrm{PM}_{10}$.

Figure 4: IRR calculated modelling lagged associations between $\mathrm{PM}_{10}$ concentrations and number of AMI. A: without controlling for other lag-effects, B: controlling for different lag-effects with constraints. IRR for changes in $10 \mu \mathrm{g} / \mathrm{m}^{3}$ of $\mathrm{PM}_{10}$.

Figure S1. Map highlighting the location of Tenerife Island in a surface dust concentration modeling forecast (shown as example, forecast for 01-Jan-2017 00:00). Source: WMO SDS-WAS (dust.aemet.es).

Figure S2. Data matrix for Poisson regression.

Figure S3. Time series of (A) $24 \mathrm{~h}$ averages $\mathrm{PM}_{10}$ concentrations in 2 air quality monitoring stations in Tenerife (B) dust concentrations in Tenerife provided by the WMO SDS-WAS modeling (starting at 2013). 


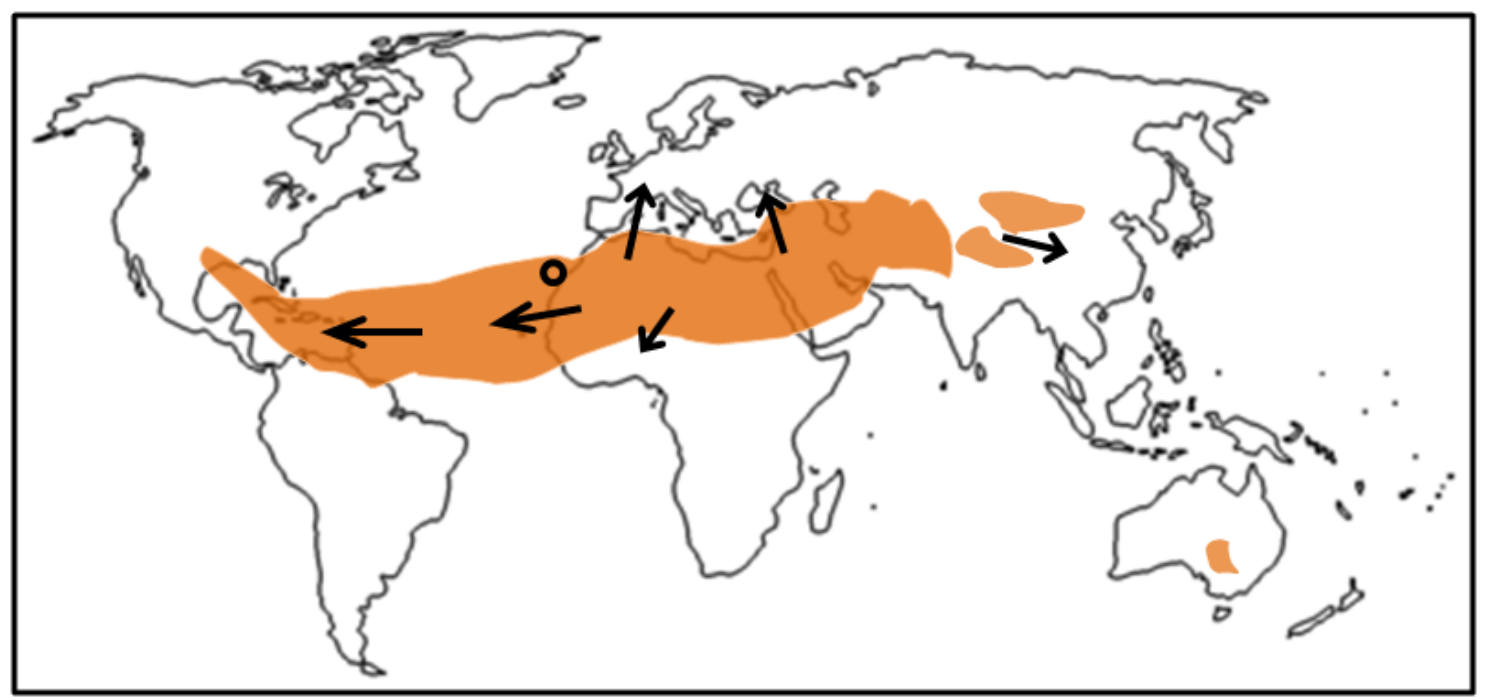

Figure 1 


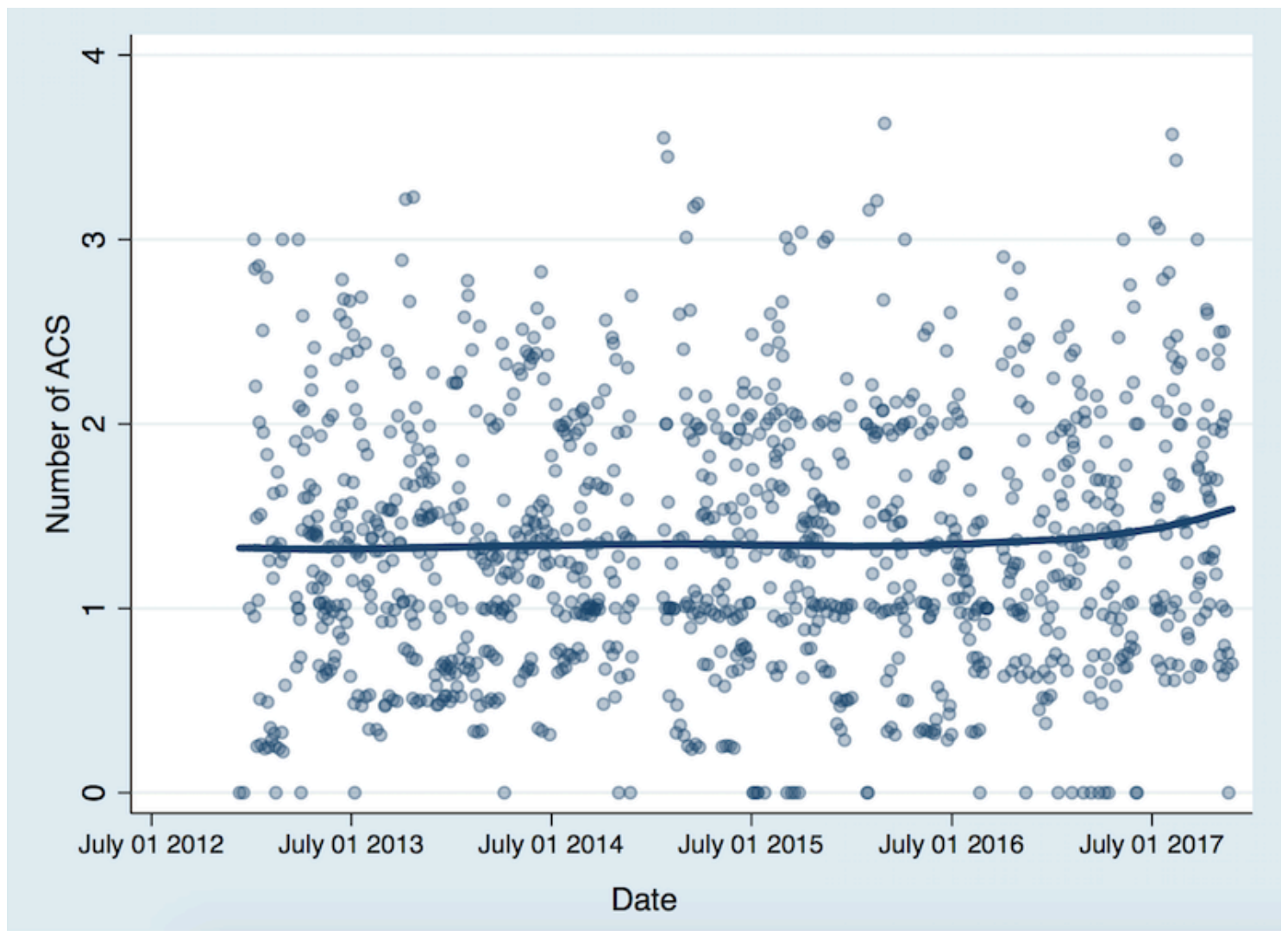

Figure 2 
Rev Esp Cardiol 2020, in press

https://doi.org/10.1016/j.rec.2020.02.003

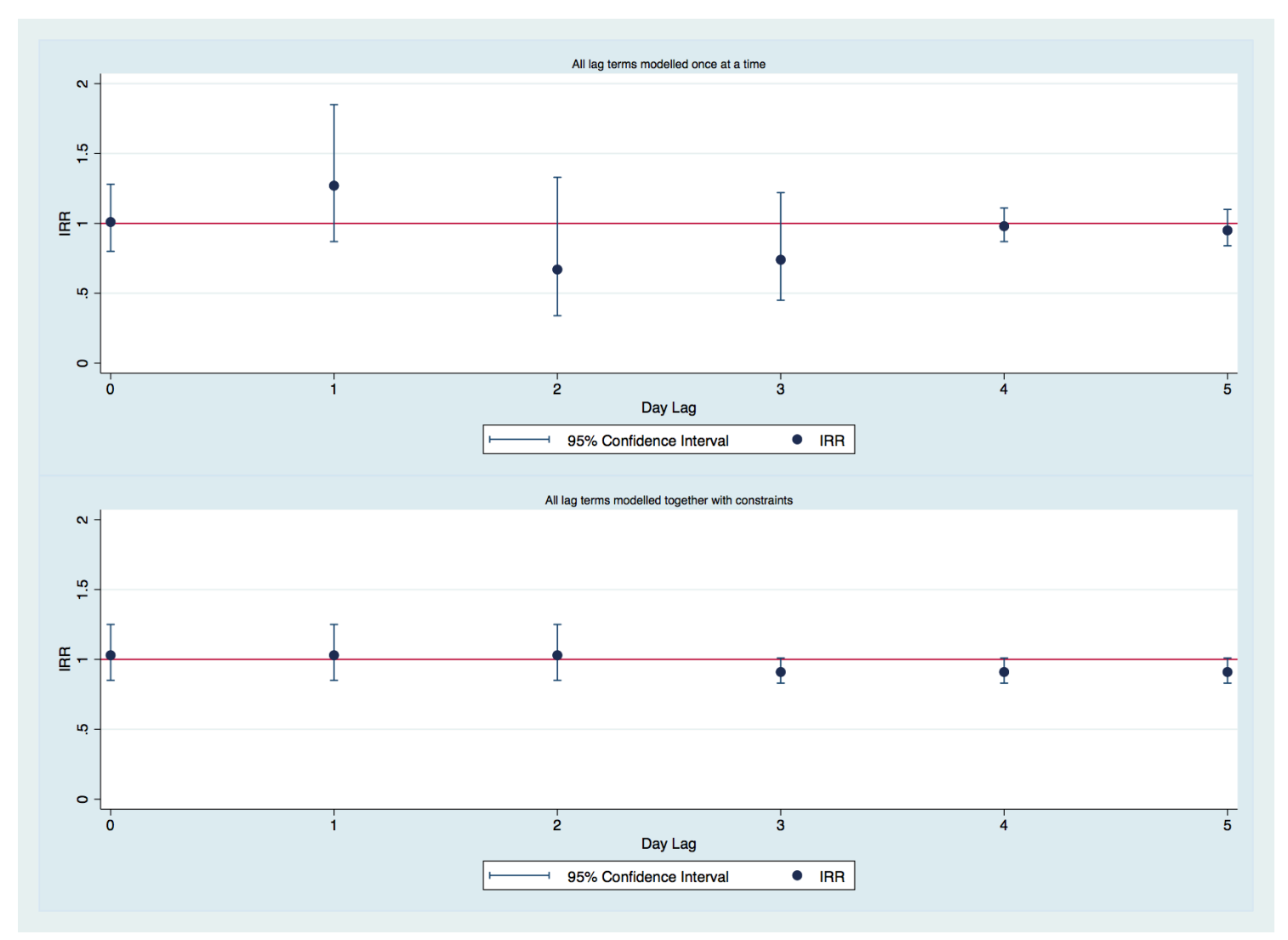

Figure 3 

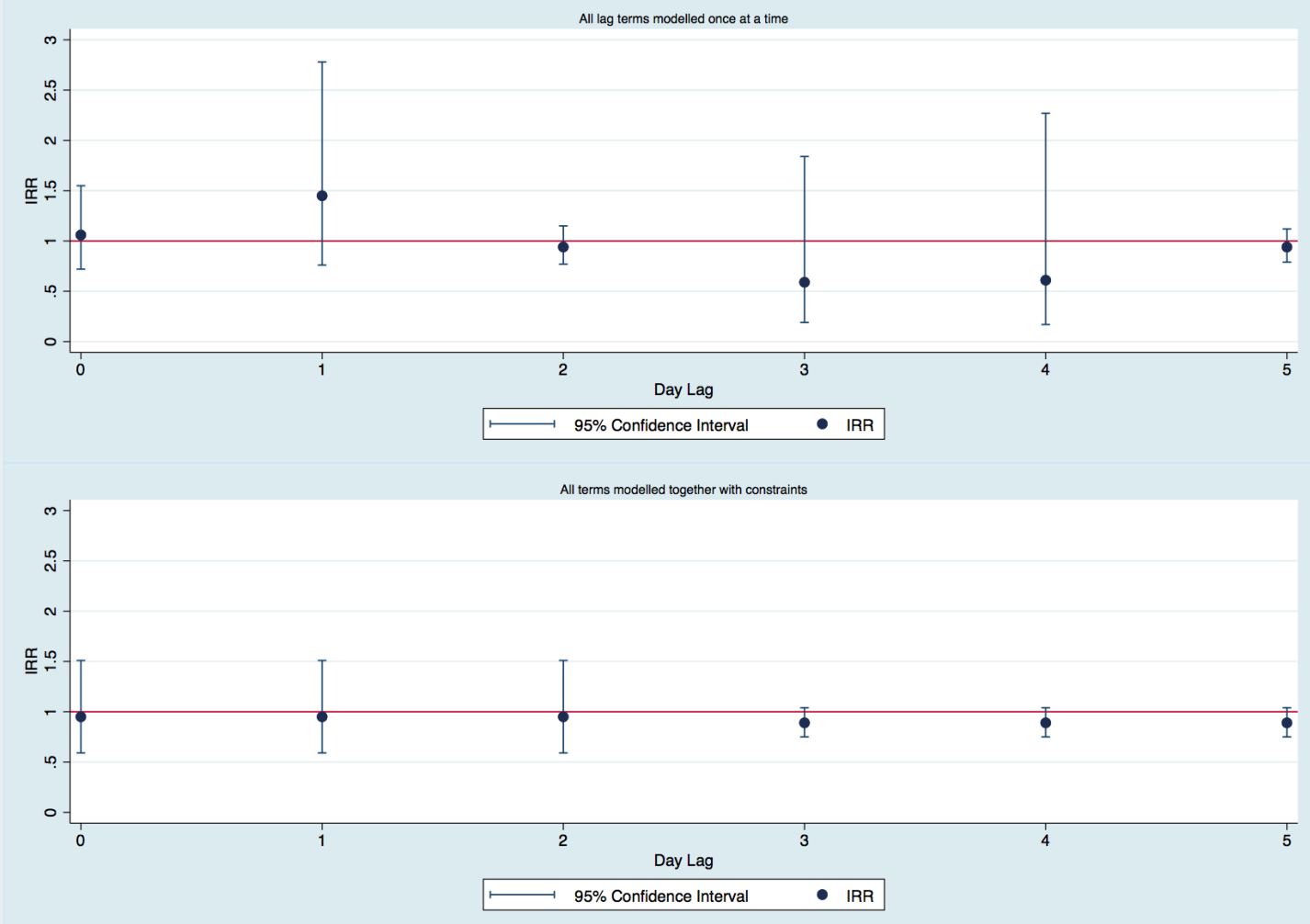

Figure 4 